\title{
LA GARANTÍA DE EJECUCIÓN PENAL A CARGo DEL JUEZ DE VIGILANCIA PENITENCIARIA A 36 AÑOS DE SU EXISTENCIA EN LA LEGISLACIÓN PENAL ESPAÑOLA*.
}

\author{
Rubén Darío Corona Torres** \\ Profesor de Derecho Penal Derecho Penitenciario y Derecho Constitucional \\ Universidad Popular Autónoma del Estado de Puebla
}

Email:

RESUMEN: La Ley Orgánica 1/1979, de 26 de septiembre, General Penitenciaria,introdujo en el Derecho Español la figura del Juez de Vigilancia Penitenciaria quien es la autoridad independiente de la Administración Penitenciaria incardinada en el Poder Judicial que tiene por objeto desempeñar una actividad jurisdiccional en la ejecución de penas y medidas de seguridad, y además controlar la legalidad de la actividad carcelaria y el sometimiento de la misma a sus fines legales, salvaguardando los derechos de los internos no afectados por el contenido del fallo condenatorio, por el sentido de la pena ni por la ley penitenciaria. Es, por tanto, un elemento fundamental del Estado Democrático de Derechoa cargo de la tutela judicial efectiva durante el cumplimiento de las consecuencias jurídicas del delito y, a su vez, garante de los derechos de los reclusos.

PALABRAS CLAVE: Política criminal, ejecución de penas y medidas, tutela judicial efectiva, vigilancia, régimen penitenciario, competencias, recursos.

\footnotetext{
*Investigación realizada como miembro del equipo de trabajo del Proyecto DER2012-35860, "Variables para una moderna política criminal superadora de la contradicción expansionista/reduccionista de la pena de prisión”, bajo la Dirección del Investigador Principal Dr. Lorenzo Morillas Cueva.

**Profesor de Derecho Penal,Derecho Penitenciario, Estructura de las Instituciones de Seguridad Pública y Derecho Constitucional, en la Universidad Popular Autónoma del Estado de Puebla; Centro Universitario Tehuacán; Instituto de Ciencias Jurídicas de Puebla y Colegio Minimalista de Ciencias Penales del mismo Estado.
} 
ABSTRACT: The General PenitentiaryOrganicLaw 1/1979, of september 26 th, introduced in theSpanishLawthe figure of PrisonSupervisionJudgewhoisindependent of theAdministrationauthorithyembodied in thejudiciarywhichaimstoplay a judicial activity in thesentences and securitymeasuresexecution, and alsoto control thelegality of prisonactivity and thesubmission of thesametotheirlawfulpurposes, saveguardingtherights of theinmatesnotaffectedby de contents of theconviction, sense of worthorthePrisonAct. He's, therfor, a fundamental element of thedemocratic rule of law in charge of effective judicial protectionforthefulfillment of the legal consecuences of thecrime and, at thesame time, guardian of therights of prisoners.

KEYWORDS: Criminal policy, sentences and measuresexecution, effective judicial protection, surveillance, penitentiarysystem, competences, challenges.

SUMARIO: I. INTRODUCCIÓN.- II. PREÁMBULO PROYECTO DE LEY DE LA LO 1/1979, DE 26 DE SEPTIEMBRE.- III. LA NATURALEZA JURÍDICA DEL JUEZ DE VIGILANCIA PENITENCIARIA.- IV. CONCEPTO DE JUEZ DE VIGILANCIA PENITENCIARIA.- V. LAS COMPETENCIAS DE LOS JUECES DE VIGILANCIA PENITENCIARIA.- VI. LAS FUNCIONES DEL JUEZ DE VIGILANCIA PENITENCIARIA. 


\section{INTRODUCCIÓN.}

Tres meses después de la entrada en vigor de la Reforma al Código Penal Español, operada por las LO 1 y 2/2015 de 30 de marzo, el Juez de Vigilancia Penitenciaria (desde ahora JVP) cumplió 36 años en el ámbito del derecho punitivo, como pieza fundamental de uno de los sectores más cuestionados, abatidos y criticados no sólo por la doctrina sino principalmente por la sociedad que es a la que sirve o debería servir para el fortalecimiento y mantenimiento de la seguridad ciudadana.

De antemano, confieso que hacer una revisión de los alcances y funcionamiento de una figura jurisdiccional en el ámbito del derecho penitenciario español no es fácil para una persona que proviene de un país latinoamericano, donde, salvo contadas excepciones, como lo es el caso de Brasil y Paraguay ${ }^{1}$, cuenta con una muy breve tradición de judicialización en la ejecución de las penas. Por citar sólo un dato, México, mi país de procedencia, inició con una práctica similar, por disposición constitucional transitoria, obligatoria para todos los estados de la República Mexicana, el 18 de junio de 2011. Desde esta perspectiva, es sumamente complicado hacer un estudio comparativo que permitiera, con holgura, identificar los aciertos y errores que en el ejercicio jurisdiccional cotidiano se van presentando por la puesta en operación de unas competencias judiciales que se diferencian cualitativamente de las ordinarias.

En consecuencia, centraré este artículo en un estudio doctrinal y legislativo español que permitan ir valorando, en la medida de mis capacidades, las implicaciones político-criminales que ha traído como consecuencia la práctica jurisdiccional en la ejecución de las penas y medidas privativas de la libertad ${ }^{2}$, así como las competencias

\footnotetext{
${ }^{1}$ FERNÁNDEZ ARÉVALO, Luis y NISTAL BURÓN, Javier; Manual de Derecho Penitenciario; $2^{\mathrm{a}}$ ed.; Ed. Thomson Reuters Aranzadi; Pamplona; 2012; págs. 762 y ss.

${ }^{2}$ Si bien es cierto, como lo apuntan FERNANDEZ ARÉVALO y NISTAL BURÓN, hasta antes de la entrada en vigor del Código Penal aprobado por LO 10/1995, de 23 de noviembre, la Ley Orgánica del Poder Judicial extendía el marco abstracto de las competencias de ejecución de los JVP a todas las medidas de seguridad, llegando incluso a atribuirle competencias en materia de penas no privativas de la libertad; no fue hasta la entrada en vigor de la LO 5/2010 cuando se restringió concretamente la intervención del JVP, otorgándole competencias únicamente en los supuestos de medidas de seguridad de internamiento y de libertad vigilada postpenitenciaria - arts. 97 y 98 del Código Penal -. Vid. Ibidem; págs. 780 y ss.
} 
que, desde diferentes ángulos, legales y reglamentarios hoy pueden deducirse con respecto al JVP.

\section{PREÁMBULO PROYECTO DE LEY DE LA LO 1/1979, DE 26 DE}

\section{SEPTIEMBRE.}

Propongo iniciar mi análisis con algunas consideraciones relacionadas con el PREÁMBULO PROYECTO DE LEY publicado en el Boletín Oficial de las Cortes núm. 148, de 15 de septiembre de 1978, mismo que a manera de exposición de motivos, sirvió como justificación parlamentaria para la entrada en vigor de la LO 1/1979, de 26 de septiembre, General Penitenciaria, publicada en el Boletín Oficial del Estado núm. 239, de 5 de octubre de 1979, (desde ahora LOGP).

En dicho documento se afirmó que la ley ya era necesaria por imperativo, principalmente, técnico y de especialización, toda vez que la doctrina lo demandaba y porque además el Código Penal (desde ahora CP) y la Ley de Enjuiciamiento Criminal (desde ahora LECrim) no eran lugares adecuados para una regulación de la ejecución de las penas y medidas de seguridad ${ }^{3}$, consistentes en privación de la libertad, aunado al hecho de que en estricta técnica jurídica, las normas reglamentarias no revestían la

\footnotetext{
${ }^{3}$ La legislación penal española, desde su promulgación en 1995 ha adoptado el sistema basado en el denominado Derecho Penal Dualista o teoría de la unificación, también denominada "doble vía", que en líneas generales es hoy día el más defendido y consolidado en occidente, el cual conceptualiza al Derecho penal, no sólo como un medio de represión, sino también un medio de prevención y lucha contra la delincuencia que, para lograr esos dos fines, junto a la pena se aplican otras sanciones de distinta naturaleza a las que se denomina medidas de seguridad. Vid. MORILLAS CUEVA, Lorenzo; Derecho Penal. Parte General; Fundamentos Conceptuales y Metodológicos del Derecho Penal. Ley Penal; $2^{\mathrm{a}}$ ed.; Dykinson; Madrid; 2010; pág. 37; ROXIN, Claus; Derecho Penal, Parte General, Tomo I; Civitas; Madrid; 2006; págs. 42 y ss.; JESCHECK-WEIGEND; Tratado de Derecho Penal. Parte General; 5 a ed.; Granada; Diciembre 2002; pág. 14; QUINTERO OLIVARES, Gonzalo; Manual de Derecho Penal. Parte General; con la colaboración deMORALES PRATS, Fermín; PRATS CANUT, José Miguel; $2^{\text {a }}$ ed.; Aranzadi; 2000; págs. 673 y s.; ZUGALDÍA ESPINAR, José Miguel; MORENO-TORRES HERRERA, María Rosa; PÉREZ ALONSO, Esteban Juan; MARÍN DE ESPINOSA CEBALLOS, Elena; RAMOS TAPIA, Ma. Inmaculada; Fundamentos de Derecho Penal. Parte General; $4^{\mathrm{a}}$ ed.; Tirant Lo Blanch; Valencia; 2010; pág. 549; JAKOBS, Günther; Derecho Penal. Parte General; Fundamentos y Teoría de la Imputación; $2^{\mathrm{a}}$ ed.; corregida; Marcial Pons, Madrid; 1997; págs. 16 y 38.; VON LISZT, Franz; Tratado de Derecho Penal; Tomo III; $4^{\text {a }}$ ed.; Reus; Madrid; 1999; pág. 197; LANDROVE DÍAZ, Gerardo; Las consecuencias Jurídicas del Delito; $3^{\mathrm{a}}$ ed.; Tecnos; Madrid; 1991; págs. 167; GRACIA MARTÍN, Luis; BOLDOVA PASAMAR, Miguel Ángel; ALASTUEY DOBÓN, M. Carmen; Lecciones de Consecuencias Jurídicas del Delito; $3^{\mathrm{a}}$ ed.; Tirant Lo Blanch; Valencia; 2004; págs. 387 y s.
} 
fijeza que demanda la consagración positiva de los derechos y deberes fundamentales de los internos ${ }^{4}$.

La anterior aseveración encontraba su fundamento legal en la promulgada casi diez meses antes, Constitución Española de 1978 (desde ahora CE), en virtud de que se consagraba en su artículo 25.2 CE que: "Las penas privativas de la libertad y las medidas de seguridad estarán orientadas a la reeducación y reinserción social y no podrán consistir en trabajos forzados. El condenado a pena de prisión que estuviere cumpliendo la misma gozará de los derechos fundamentales de este capítulo, a excepción de los que se vean expresamente limitados por el contenido del fallo condenatorio, el sentido de la pena y la ley penitenciaria. En todo caso, tendrá derecho a un trabajo remunerado y a los beneficios correspondientes de la Seguridad Social, así como al acceso a la cultura y al desarrollo integral de su personalidad..."

A partir de esta consideración de máxima entidad legal, en el ámbito jurídico y político se supuso en una primera aproximación que, el Estado Español se adhería a un criterio político criminal que era producto del Derecho penal liberal, en donde la pena ya no tiene un carácter de mera retribución, de castigo por el mal causado, de expiación del infractor. Se adoptaba así, formalmente, una institución que, aunque ya de larga tradición en España, ahora se reconstruía con el objetivo de resolver problemas humanos, y así desde entonces, por lo menos con carácter programático, la pena tendría la tarea de prevenir futuros delitos. ${ }^{5}$

Dicha ubicación en sede Constitucional, implicaba por lo demás, que derivado también de la adopción de una postura liberal de Estado, era necesario que el principio de legalidad permeara a todas las facetas en donde se aplica y con las que se cumplen o se pretenden cumplir los fines del derecho penal y en consecuencia las penas y medidas de seguridad consistentes en privación de la libertad, puesto que si el legislador democrático representaba la soberanía nacional, los delitos y las penas, que suponen

\footnotetext{
${ }^{4}$ MONTERO HERNANZ, Tomás; Legislación Penitenciaria Comentada y Concordada; $1^{\mathrm{a}}$ ed.; Ed, La Ley Grupo WoltersKluwer; España; 2012; pág. 51 y s.

${ }^{5}$ BORJA JIMÉNEZ, Emiliano; Curso de Política Criminal; 2a ed.; Ed. Tirant lo Blanch, 2011; pág. 45.
} 
siempre restricción de libertad de los ciudadanos firmantes del pacto, sólo pueden venir determinados por la representación de esa voluntad general que es la ley. ${ }^{6}$

Por ello no se ha dudado en establecer en la doctrina que, al establecer la CE la categoría de leyes orgánicas, cuya aprobación o modificación necesita de una mayoría cualificada en el Congreso, para regular, entre otras materias, el desarrollo de los derechos fundamentales y de las libertades públicas, según su artículo 81, la cualificación de Orgánica a la Ley General Penitenciaria de 26 de septiembre de 1979, se ha debido a la consideración de la materia penal, como materia que afecta directamente a los derechos fundamentales y a las libertades públicas. ${ }^{7}$

Por otro lado, pese a que antes de la introducción del JVP en España, existían en la LECrim de 14 de septiembre de 1882, los arts. 526, 984, 985, 987 y 990 ${ }^{8}$, mismos que contenían como común denominador la ejecución de las sentencias y con ello el mandato, para autoridades jurisdiccionales y no administrativas, de ejercer funciones relacionadas con la ejecución de las penas privativas de la libertad, todo ello traía como consecuencia, en la práctica, que el internamiento del recluso constituyera el principio del cumplimiento material de la pena y esa tarea estaba a cargo de los servicios de prisiones. No obstante el art. 985 LECrim preceptuaba que la competencia de Jueces y Tribunales sentenciadores, durante la fase del cumplimiento de las penas, no cesaba y, adicionalmente el art. 990.4 LECrim agregaba facultades de inspección atribuibles a las mismas autoridades jurisdiccionales citadas con antelación, las cuales se materializaban a través de visitas, sin embargo el art. 526 LECrim había previsto dichas visitas respecto de los detenidos y presos, es decir no existía una disposición análoga en la LECrim para los penados. Por ello en 1978, antes de aprobarse la CE, existía una convicción doctrinal generalizada de que, una vez ingresado en prisión el reo, la actividad de los órganos jurisdiccionales cesaba, hasta el momento en que surgiera eventualmente un

\footnotetext{
${ }^{6}$ Ibidem.

${ }^{7}$ ALONSO DE ESCAMILLA, Avelina; El Juez de Vigilancia Penitenciaria; $1^{a}$ ed.; Ed. Civitas; Madrid; 1985; pág. 103. Vid. En el mismo sentido, pero desde una perspectiva de política criminal los planteamientos de BORJA JIMÉNEZ, Emiliano; Curso ...cit.; pág. 54.

${ }^{8} \mathrm{Vid}$. Las diferentes opiniones, con respecto a estos artículos en ALONSO DE ESCAMILLA, Avelina; El Juez...cit.; págs. 118 y 129; FERNÁNDEZ ARÉVALO, Luis y NISTAL BURÓN, Javier; Manual... cit.; págs. 763 y ss; TAMARIT SUMALLA, Josep-María; GARCÍA ALBERO, Ramón; SAPENA GRAU, Francisco y RODRÍGUEZ PUERTA, María-José; Curso de Derecho Penitenciario; $1^{\text {a }}$ ed.; Ed. Tirant lo Blanch; Valencia; 2001; pág. 293.
} 
incidente(acumulación jurídica de penas o enajenación mental sobrevenida) o bien la necesidad de declarar modificada o extinguida la pena. En esta época, las visitas penitenciarias de los Tribunales habían caído en el desuso, y las facultades de inspección no solo no habían sido desarrolladas, sino que incluso el propio reglamento de servicios de prisiones aprobado por Decreto de 2 de febrero de 1956 (entonces vigente), había tenido buen cuidado de vaciarlas de contenido, al proscribir que pudieran afectar el régimen y disciplina del Establecimiento ${ }^{9}$.

En el mismo preámbulo que seguimos comentando, se señaló que la LOGP, pretendía colmar la laguna legal que se venía produciendo hasta su elaboración legislativa y evidente entrada en vigor, comprendiendo en ella las normas fundamentales relativas al estatuto jurídico del interno, las funciones y cometidos de la Administración Penitenciaria, la competencia del Juez de Vigilancia de ejecución de las penas, de nueva creación en el ordenamiento español, entre otras.

Con respecto a este último, cabe resaltar que en la exposición de motivos se mezclaron indiscriminadamente las dos variantes posibles de denominación para la función jurisdiccional en la ejecución de las penas y medidas privativas de libertad, es decir por un lado "Juez de Vigilancia” y por el otro "Juez de Ejecución de las Penas".

Sobre el particular, basta decir, para zanjar la aparente indecisión legislativa, lo siguiente:

En primer lugar los JVP no entraron en funcionamiento hasta el 1 de octubre de 1981, tras la entrada en vigor del Reglamento Penitenciario (desde ahora RP). Al tiempo de publicarse este último, aprobado en virtud de Real Decreto (desde ahora RD) 1201/1981, de 8 de mayo, aun no se habían creado dichos juzgados, y por ello la Disposición Transitoria (desde ahora DT) $5^{\mathrm{a}}$ del RP/1981 contenía un claro recordatorio sobre el retraso de la creación de estos órganos judiciales. Fue así como por Acuerdo del Consejo General del Poder Judicial (desde ahora CGPJ) de 9 de julio de 1981 aprovechó básicamente la planta de los antiguos Juzgados de Peligrosidad y Rehabilitación Social que pasaron a reconvertirse en JVP, si bien adaptados al nuevo mapa autonómico, a la ubicación de los Establecimientos Penitenciarios, y a la

\footnotetext{
${ }^{9}$ FERNÁNDEZ ARÉVALO, Luis y NISTAL BURÓN, Javier; Manual... cit.; págs. 763 y ss.
} 
población reclusa albergada en aquéllos. De este modo, un nuevo acuerdo del CGPJ determinó el inicio de la andadura de los JVP el 1 de octubre de $1981 .^{10}$

En segundo lugar, casi seis años después de la LOGP, el art. 26 de la LO 6/1985 de 1 de julio, del Poder Judicial; expresamente los denominó "Juzgados de Vigilancia Penitenciaria", considerándolos depositarios del ejercicio de la potestad jurisdiccional y los incardinó dentro de la planta jurisdiccional española, estableciéndolos asimismo como un órgano unipersonal diferenciado de cualquier otro, y cuyos titulares ejercerían en exclusiva las funciones propias de la ejecución de las penas privativas de libertad y sus incidencias o, la distribución de su demarcación y planta judicial en un primer momento en la DT $27^{\text {a }}$ de la LOPJ y posteriormente en la Ley 38/1988, de 28 de diciembre, de demarcación y planta judicial ${ }^{11}$.

Finalmente, en tercer lugar el art. 94.1 de la LOPJ establece de manera clara y precisa la denominación de aquellos juzgados, mismos que tendrán las funciones jurisdiccionales previstas en la LOGP en materia de ejecución de penas privativas de libertad y medidas de seguridad, denominándolos JVP.

Es más, la propia CE desde su promulgación establecía en su art. 117.3 lo siguiente: "El ejercicio de la potestad jurisdiccional en todo tipo de procesos, juzgando y haciendo ejecutar lo juzgado, corresponde exclusivamente a los Juzgados y Tribunales determinados por las leyes, según las normas de competencia y procedimiento que las mismas establezcan...”. De esta manera se puede afirmar que el JVP es, por ello, consecuencia directa de la independencia del poder judicial, poder al que corresponde juzgar pero también "hacer ejecutar lo juzgado", , aspecto que según GARCÍA ALBERO, si bien no hay que confundir con la ejecución "por sí" de lo juzgado, sí que impone el control de los elementos esenciales que definen la propia pena, y que más allá de su duración nominal, afecta a su contenido. ${ }^{13}$

\footnotetext{
${ }^{10}$ Ibidem, pág. 765.

${ }^{11}$ Vid. En este sentido MARTÍN DIZ, Fernando; El Juez de Vigilancia Penitenciaria; $1^{\mathrm{a}}$ ed.; Ed. Comares; Granada; 2002; pág. 62.

${ }^{12}$ Ibidem, pág. 19. En el mismo sentido RODRÍGUEZ ALONSO, Antonio-RODRÍGUEZ AVILÉS, Juan Antonio; Lecciones de Derecho Penitenciario; $4^{\mathrm{a}}$ ed.; Ed. Comares; Granada; 2011; pág. 51.

13 TAMARIT SUMALLA, Josep-María; GARCÍA ALBERO, Ramón; SAPENA GRAU, Francisco y RODRÍGUEZ PUERTA, María-José; Curso ...cit.; pág. 294.
} 
Con mayor ímpetu, otros autores consideran al JVP como una pieza fundamental "en torno a la cual gira todo el sistema español de ejecución de penas privativas de la libertad y elemento relevante de la jurisdiccionalización constitucionalmente demandada de la ejecución de la pena privativa de libertad, dado que la configuración legal del JVP le atribuye competencia para hacer cumplir efectivamente dicha pena, resolver los recursos e impugnaciones que dentro de la vida penitenciaria pueda plantear un recluso, corregir los abusos y desviaciones que en el cumplimiento del régimen penitenciario puedan producirse y especialmente, la prerrogativa que entendemos estratégicamente básica cara a la reeducación y reinserción social del penado, ciudadano y miembro de la sociedad en todo momento y en todo caso, cual es la de salvaguardar sus derechos...",14

En similar sentido, el Tribunal Constitucional se ha pronunciado al respecto, al determinar en la STC 2/1987, de 21 de enero, que la aparición del JVP "supone una potenciación del momento jurisdiccional de la ejecución de las penas, que en nuestro ordenamiento se realiza confiando a un Juez, esto es, a un órgano independiente del poder administrativo, el control sobre las diversas fases de ejecución y en particular sobre la protección de los derechos de los detenidos"

Ahora bien, con referencia al papel también protagonista que corresponde a la sociedad, aludido en el preámbulo en comento, y con respecto más puntualmente a la imagen que hoy en día tiene aquella sobre la Administración Penitenciaria en general y la del JVP en específico, se afirma que se ha visto seriamente perjudicado por el exceso de medios de comunicación de tendencia amarillista - y porque no decirlo de la considerable audiencia que los sigue - imperante en los últimos tiempos y que hace de ese Juez uno de sus elementos tremendistas y escabrosos favoritos en la atribución de responsabilidades cuando algunas de sus decisiones, siempre sujetas a la más estricta legalidad como órgano perteneciente al poder judicial que es, genera bien la comisión de hechos delictivos por algún recluso, bien su no regreso al Establecimiento Penitenciario, o simplemente alarma social con la consiguiente polémica, circunstancias de las cuales hacen profusa publicidad los medios de comunicación y que han generado

\footnotetext{
${ }^{14}$ MARTÍN DIZ, Fernando; El Juez...cit. págs. 54 y ss.

${ }^{15}$ Ibidem, págs. 67 y ss.
} 
en la sociedad una cierta animadversión y desconfianza hacia estos órganos jurisdiccionales ${ }^{16}$.

No cabe duda que la imbricación del JVP en el ámbito penal en general y específicamente en el Derecho penitenciario, ambos de por si en crisis de credibilidad con respecto a su eficacia, ha traído como consecuencia lógica la misma incredulidad sobre su papel preponderante al momento de materializar el encarcelamiento punitivo de los delincuentes. Pero todo ello no es más que el producto de una política de "ley y orden" auspiciada exageradamente por los medios de comunicación de masas que promocionan una política penitenciaria que cumpla una función de "incapacitación social" del delincuente encaminada a que este no dañe la sociedad durante el tiempo que se encuentre internado y por lo tanto, para el lego es complicado entender cómo puede existir un funcionario del poder judicial o de cualquier otro poder del Estado, incluyendo a la propia administración penitenciaria, que vele por los derechos de aquellas personas que han transgredido la ley y mucho menos resulta comprensible cómo los esfuerzos tanto de la administración penitenciaria como de su jurisdicción especial puedan encargarse de ofrecer un tratamiento rehabilitador y mecanismos judiciales para los reclusos, incluso para poder lograr libertades anticipadas, en el caso de ciertas penas consideradas hoy en día no graves. Este es un tema pendiente definitivamente de la política criminal que debe empezar a revertirse, o quizá ya esté siendo revertido a través de la entrada en vigor de ciertas penas que neutralizan la posibilidad de seguir manteniendo el sistema progresivo, ya que precisamente, el éxito de éste depende en gran medida de los incentivos que se puedan ofrecer como alternativas para que los reclusos puedan ir mejorando en su comportamiento al interior de las prisiones, coadyuvando con esto a la seguridad interior de los establecimientos penitenciarios, y sentando, a su vez, las bases de una cultura de solidaridad con la sociedad que le vaya permitiendo a la población penitenciaria, internalizar modelos de conducta similares, que le hagan más fácil su reincorporación efectiva a la vida social en libertad.

Esta opinión personal y otras más con respecto al escrutinio público podrían distraer el objetivo de la propuesta que se viene planteando, por lo que, dejaré, por el momento, la oportunidad para una posterior reflexión.

${ }^{16}$ Ibidem, pág. 54 
Así las cosas, también se afirmó que, para la redacción de la LOGP, se tomaron en cuenta principalmente, junto a las conclusiones de la ciencia penitenciaria de su tiempo (1978), las Reglas Mínimas para el Tratamiento de los Reclusos elaboradas por Naciones Unidas y el Consejo de Europa, los pactos internacionales sobre derechos humanos, las leyes penitenciarias de los países más avanzados y el anteproyecto de CE.

Al hilo de las manifestaciones vertidas por el legislador en el párrafo inmediato anterior, cabe hacer la siguiente reflexión: si bien es cierto, desde entonces y hasta ahora, todavía, un sector de la doctrina, se plantea la autonomía de la Ciencia Penitenciaria $^{17}$, también lo es el hecho de que al interior de la Dogmática Jurídico Penal es donde se puede observar desde, prácticamente sus inicios, el abordaje teórico de uno de sus conceptos básicos como lo es la pena. Sobre el particular, junto a la Teoría de la ley penal y la teoría del delito, la teoría de la pena es el lugar donde se ha desarrollado una extensa producción doctrinal relativa a su función y fines.

Dentro de la última de las teorías aludidas en el párrafo inmediato anterior encontramos a la Nueva Defensa Social, considerada por LANDROVE DÍAZ como una teoría mixta o de la unión. Su aportación a las teorías de los fines de la pena se debe en principio, de acuerdo con ROXIN ${ }^{18}$, a GRAMATICA quien crea en 1947 la Sociedad Internacional para la Defensa Social y donde se dice continuaron desarrollando las ideas de FFRANZ VON LISZT. Posteriormente, MARC ANCEL realiza el libro titulado La defensesocialenouvelle(La nueva defensa social), aparecido en París en 1954, mismo que puede ser considerado como la partida de nacimiento de esta tendencia. Los puntos concretos de la nueva defensa social son: se afirma que el delincuente no debe ser sometido a la justicia penal con un fin de expiación, venganza o retribución; la política criminal que se trata de imponer está orientada al tratamiento del delincuente, con la concreta finalidad de devolver al autor del delito a una vida social libre y consciente; para alcanzar la resocialización del delincuente debe realizarse un meticuloso estudio científico de su personalidad; el tratamiento del delincuente desemboca, desde la óptica defensista, en una reorganización del sistema actual de los medios de reacción propios y exclusivos del Derecho penal: lo que se ha dado en llamar una integración racional de la pena y de la medida de seguridad.

\footnotetext{
${ }^{17}$ RODRÍGUEZ ALONSO, Antonio-RODRÍGUEZ AVILÉS, Juan Antonio; Lecciones...cit.; págs. 1 y ss. ${ }^{18}$ ROXIN, Claus; Derecho Penal, ...cit.; pág. 86.
} 
Para LANDROVE DÍAZ esta última teoría, es la que subyace a las Reglas Mínimas Sobre el Tratamiento de los Reclusos elaboradas por las Naciones Unidas, las cuales fueron redactadas en el Primer Congreso de las Naciones Unidas sobre Prevención del Delito y Tratamiento del Delincuente, celebrado en Ginebra en el año de 1955, mismas que fueron aprobadas por el Consejo de las Naciones Unidas en Resolución 663 C I (XXIV) de 31 de julio de $1957^{19}$.

Por su parte, en el seno del Consejo de Europa, el Comité Europeo de Problemas Criminales procedió a partir de 1967 a una revisión de las Reglas Mínimas de las Naciones Unidas de 1955, teniendo en cuenta los cambios producidos en el marco europeo y en las ideas sobre el tratamiento del delincuente, "ante la posibilidad de que los Estados miembros pudieran encontrar un denominador común más amplio y liberal que el admitido a nivel mundial”. El texto refundido de las Reglas Mínimas del Consejo de Europa fue adoptado por el Comité de Ministros por resolución 5 (73) de 19 de enero de 1973, recomendando a los gobiernos de los Estados miembros para que, en su legislación y en su práctica, incorporen los principios expuestos en dichas Reglas Mínimas; mismas, que según el acuerdo mayoritario en la doctrina, han tenido una influencia fundamental en España para la introducción del JVP, en la LOGP. ${ }^{20}$ Especialmente en su art. 56.2 se establecía la recomendación de que con el fin de respetar los derechos de los reclusos y al principio de legalidad debería de existir un órgano en las cárceles, judicial o no, pero si exterior y distinto a la propia Administración.

Resta decir en el presente capítulo, como se ha dejado patente en la doctrina, el legislador español a la hora de diseñar como debía quedar sometida a control judicial la actuación de la administración penitenciaria, tenía ante sí tres modelos que el derecho comparado ya le brindaba: el alemán, el francés y el italiano.

\footnotetext{
${ }^{19}$ LANDROVE DÍAZ, Gerardo; Las consecuencias ... cit.; pág. 60.

${ }^{20}$ Vid. En este sentido FERNÁNDEZ ARÉVALO, Luis y NISTAL BURÓN, Javier; Manual...cit.; pág. 762; MIR PUIG, Carlos; Derecho Penitenciario. El Cumplimiento de la Pena Privativa de Libertad; $3^{\mathrm{a}}$. ed.;Ed. Atelier; Barcelona; 2015; pág. 228; MONTERO HERNANZ, Tomás; Legislación Penitenciaria...cit.; pág. 41; PÉREZ CEPEDA, Ana Isabel; Lecciones y Materiales para el Estudio del

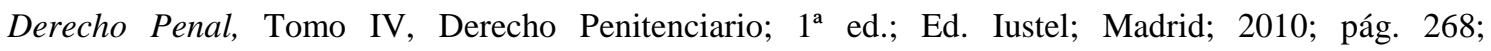
RODRÍGUEZ ALONSO, Antonio-RODRÍGUEZ AVILÉS, Juan Antonio; Lecciones...cit.; pág. 32; TAMARIT SUMALLA, Josep-María; GARCÍA ALBERO, Ramón; SAPENA GRAU, Francisco y RODRÍGUEZ PUERTA, María-José; Curso ...cit., pág. 294.
} 
A. El antecedente alemán.

El control judicial de la actuación administrativa de ejecución de las penas privativas de la libertad es llevado a cabo por los tribunales ordinarios, los cuales sólo entran a conocer del asunto cuando existe un recurso planteado ante ellos y nunca de oficio.

B. El antecedente francés.

La intervención judicial en el ámbito penitenciario se efectúa a través de los llamados jueces de ejecución de penas, los cuales, en realidad, más que funciones de control a la Administración despliegan sus competencias en aspectos estrictamente penológicos, tales como acumulación de condenas, aprobación de beneficios penitenciarios, permisos de salida, licenciamientos, etc. (art. 722 del Código Procesal Penal galo) o el Tribunal de Vigilancia Penitenciaria Italiano (art. 70 de la Ley Penitenciaria italiana).

C. El antecedente italiano.

Un tercer gran modelo es el que opta porque el control de la Administración Penitenciaria lo realice una jurisdicción especial que se alza como auténtica garante de los derechos de los reclusos, no sólo por la vía del recurso sino también por su directo conocimiento de la prisión, pudiendo llegar a hacer sugerencias en temas estrictamente administrativos. Son los llamados Jueces de Vigilancia Penitenciaria que ya existían, desde 1975, en Italia.

Pues bien, de todos es sabido que la LOGP optó en su redacción originaria por este tercer modelo ${ }^{21}$.

\section{III.LA NATURALEZA JURÍDICA DEL JVP.}

Como ha quedado ilustrado someramente en el capítulo anterior desde la entrada en vigor de la LOGP se han presentado diversos inconvenientes para la instauración de

\footnotetext{
${ }^{21}$ GARCÍA VALDÉZ, Carlos; Competencias del Juez de Vigilancia Penitenciaria. Necesidad de asumir nuevas competencias. En Cuadernos de Derecho Judicial. N ${ }^{\circ}$ XVII .Derecho Penitenciario II, Dir. De Castro Antonio. 2003, págs. 82 y ss.
} 
la jurisdicción penitenciaria. Una de las primeras discusiones en el ámbito de la doctrina destaca en el sentido de plantear cuál es la naturaleza jurídica de los JVP, existiendo en la actualidad divergentes opiniones con respecto a la misma, por ejemplo, según las palabras del máximo, GARCÍA VALDÉZ, artífice de la LOGP, era partidario de que el JVP español no fuera un híbrido juez-agente penitenciario, sino una autoridad judicial especializada e independiente, y este planteamiento se basaba en el siguiente argumento: "es necesario que quede diáfana la separación entre las atribuciones de la administración penitenciaria y la de los JVP y no puede producirse una invasión de aquellas por las de éste pues sería como venir a reconocer facultades de dirección del establecimiento a toda autoridad judicial ${ }^{22}$.

Su preocupación con respecto al asunto aquí esbozado partía de una concepción que en su época estaba adquiriendo relevancia doctrinal con respecto a la cuestión de si la jurisdicción penitenciaria constituía un auténtico órgano jurisdiccional o un órgano híbrido, a caballo entre la jurisidiccionalidad y la administratividad. ${ }^{23}$

La naturaleza híbrida encontraba asidero fundamentalmente en tres interpretaciones:

En primer lugar, que ostenta unas funciones de propuesta de mejora organizativa - art. 77 LOGP - inéditas entre los órganos jurisdiccionales.

En segundo lugar, que ostenta unas competencias de propuesta de revisión de las medidas de seguridad - art. $97 \mathrm{CP}$-, siendo así que la jurisdiccionalidad radica en la resolución decisoria, que el precepto legal precitado atribuye al juez o Tribunal sentenciador.

Y finalmente, que el JVP además asume unas funciones peculiares de conocimiento de daciones de cuenta de actos administrativos de ejecutividad diferida tales como la aprobación de sanciones de aislamiento en celda - cuya duración exceda de catorce días, art. 76.2. d) LOGP ${ }^{24}$.

\footnotetext{
${ }^{22}$ ALONSO DE ESCAMILLA, Avelina; El Juez...cit., pág. 29.

${ }^{23}$ FERNÁNDEZ ARÉVALO, Luis y NISTAL BURÓN, Javier; Manual...cit.; pág. 766.

${ }^{24}$ Ibidem.
} 
Por otro lado, la naturaleza jurisdiccional, hoy día reconocida por la doctrina mayoritaria, fundamenta esta concepción en la aceptación del espíritu de la Ley y en consecuencia de los objetivos mediatos que pretendía conseguir el legislador al elaborar la LOGP, sobre todo para cumplir con las exigencias que imponía el Estado de Derecho, tras la promulgación de la Constitución de 1978, derivadas: de un lado, del principio de legalidad (art. 9.3 CE), que en la ejecución de las penas pretende evitar que la Administración penitenciaria pueda variar, sin control judicial adicional, el sentido del fallo condenatorio; de otro lado, de la competencia exclusiva que atribuye la $\mathrm{CE}$ a los Jueces y Tribunales de ejecutar lo juzgado (art. 117.3 CE). Así como la previsión del art. 25.2 CE, al pronunciarse abiertamente, en el párrafo primero, a favor del fin resocializador de las penas y medidas de seguridad, y en el párrafo segundo, por la garantía expresa de la tutela de los derechos de los presos que no estén afectados por la sentencia, en el sentido de la pena y la Ley ${ }^{25}$.

\section{IV.CONCEPTO DE JVP}

Con la finalidad de iniciar una propuesta sistemática personal, resulta necesario plantear, antes de pasar a exponer las diversas competencias que el JVP tiene conforme a la legislación penitenciaria vigente un concepto que pueda sintetizar de manera coherente la actividad jurisdiccional en la materia.

De esta forma, el JVP es la autoridad independiente de la Administración Penitenciaria incardinada en el Poder Judicial español que tiene por objeto desempeñar una actividad jurisdiccional en la ejecución de penas y medidas de seguridad, y además controlar la legalidad de la actividad penitenciaria y el sometimiento de la misma a sus fines legales, salvaguardando los derechos de los internos no afectados por el contenido del fallo condenatorio, por el sentido de la pena ni por la ley penitenciaria.

\section{LAS COMPETENCIAS DE LOS JVP}

Es evidente, aunque cada vez menos por los esfuerzos que los JVP han emprendido con sus reuniones anuales para paliar la dispersión de criterios que se han ido adoptando en las resoluciones de los asuntos sometidos a su jurisdicción, que todavía hasta hoy existen lagunas orgánicas y procesales en la legislación penitenciaria española. No ha bastado para recomponer este escenario la propuesta de un Proyecto de

${ }^{25}$ PÉREZ CEPEDA, Ana Isabel; Lecciones...cit.; pág. 268. 
Ley Orgánica reguladora del Procedimiento ante los Juzgados de Vigilancia Penitenciaria de 4 de abril de 1977. Dicho proyecto, en su Exposición se Motivos comienza por reconocer que, hasta el momento, falta un cuerpo procesal completo de aplicación a los incidentes de ejecución de las penas privativas de libertad o control jurisdiccional de la actuación de la Administración Penitenciaria atribuidos a los JVP, para pasar a fijar como sus objetivos, el dar respuesta a los dos problemas esenciales: primero, la delimitación de las competencias de dichos jueces y la de los órganos sentenciadores en lo que afecta a la ejecución de penas privativas de la libertad y medidas de seguridad; y segundo, el establecimiento, al propio tiempo, de las normas de procedimiento reguladoras de la actuación de los repetidos juzgados y de la intervención ante ellos. $^{26}$

Ésta cualificada por RACIONERO CARMONA "desidia legislativa",27, ha generado en la doctrina española, lejos de la parálisis intelectual, un gran número de propuestas de sistematización con respecto a las competencias de los JVP, de las cuales las más significativas a mi juicio son las siguientes:

En primer lugar, aquellas que proponen dividir las competencias del JVP, partiendo de sus dos funciones principales:

a) Jurisdicción en la ejecución de las penas privativas de libertad, y

b) Jurisdicción de control contencioso-administrativo.

Con la anterior división, se colige que el JVP tiene las siguientes competencias:

1.- Relativas a la Ejecución de la Pena.

2.- Relativas a la ejecución de medidas.

3.- Competencias de protección de los derechos de los internos, y

4.- Competencia consultiva de formular propuestas a la Dirección General de Instituciones Penitenciarias (art. 77 LOGP) ${ }^{28}$

\footnotetext{
${ }^{26}$ ESTÉVEZ JIMENO, Ángel D.; En Cuadernos...cit.; págs. 149 y ss.

${ }^{27}$ RACIONERO CARMONA, Francisco; En Cuadernos... cit.; p. 100.

${ }^{28}$ PÉREZ CEPEDA, Ana Isabel; Lecciones...cit.; págs. 270-283.
} 
En segundo lugar, existe una postura procesalista que categoriza las funciones del JVP desde la perspectiva de las distintas instancias que se pueden agotar durante el proceso penal o administrativo.

De esta manera dicha propuesta las clasifica de la siguiente manera:

a) Funciones decisorias en primera instancia.

b) Resolutorias en segunda instancia.

c) Competencias de dación de cuentas o de conocimiento, y

d) Funciones asignadas por el $\mathrm{CP}^{29}$

En tercer lugar, existen aquellas con un afán reduccionista, quizá pedagógico en apariencia, y que en principio concretan las funciones en tres grandes órdenes, aunque posteriormente desarrollan, por separado, algunas situaciones que se escapan a la clasificación propuesta:

a) Funciones "decisorias"

b) Funciones de Vigilancia, y

c) Funciones de propuesta o consultivas. ${ }^{30}$

Por último, se contienen en la doctrina varias propuestas más que apuestan por un análisis exegético que permite hacer una revisión puntual de toda la legislación penitenciaria vigente a través de la clásica jerarquía de las leyes propuesta por Kelsen, misma que hemos ido desarrollando en estas líneas, y que, aunque pudiera dejar algunas dudas u opiniones encontradas, sienta las bases para una mejor metodología de estudio relacionada con la materia jurisdiccional penitenciaria que puede ser completada y mejorada a través de la jurisprudencia del Tribunal Constitucional, sin pasar por alto, aunque no tienen carácter vinculante, toda una serie de recomendaciones aprobadas por los JVP en las reuniones periódicas ${ }^{31}$ que vienen celebrando desde 1981 y que han dado

\footnotetext{
${ }^{29}$ CERVELLÓ DONDERIS, Vicenta; Derecho Penitenciario; $3^{\mathrm{a}}$ ed.; Ed. Tirant lo Blanch; Valencia; 2012; págs. 142-146.

${ }^{30}$ MIR PUIG, Carlos; Derecho Penitenciario...cit.; págs. 231-232.

${ }^{31}$ RODRÍGUEZ ALONSO, Antonio-RODRÍGUEZ AVILÉS, Juan Antonio; Lecciones...cit.; págs.54 y ss.
} 
lugar a los Criterios Refundidos de Actuación, de los cuales se tienen memoria hasta el año $2010 .^{32}$

Desde esta perspectiva, el marco competencial del JVP viene definido por todo un conjunto de normas y disposiciones legales que a continuación se enlistan:

a) Los arts. 76 a 78 LOGP.

b) La LOPJ, reformada por LO 16/1994, de 8 de noviembre, arts. $92^{33}, 94$ y 95 y DA $5^{\text {a }}$ modificada por la Ley 7/2003, de 30 de enero de medidas de reforma para el cumplimiento íntegro y efectivo de las penas, sobre recursos que cabe interponer contra las resoluciones del JVP. ${ }^{34}$

c) La Ley 38/1988, de 28 de diciembre, de Demarcación y Planta que ha venido a sustituir los acuerdos del Consejo General del Poder Judicial que atribuían las competencias como JVP a otros órganos jurisdiccionales.

d) El CP vigente, reformado por LO 15/2003 y luego modificada mediante la LO 5/2010, art. 36.2, que introdujo el periodo de seguridad; art. 78 en concordancia con el art. 76, sobre el cumplimiento efectivo de las penas privativas de libertad; arts. 90.2, 91 y 93 referentes a libertad condicional; 97 y 98, a las medidas de seguridad, y 105 de las medidas no privativas de libertad.

e) La LECrim por remisión a los arts. 526, 985, 987, 989, en su nueva redacción conforme a la LO 7/2003 en relación con los nuevos pronunciamientos sobre la responsabilidad civil derivada del delito y falta y concordantes que hacen la DT $1^{\mathrm{a}}$ de la LOGP.

\footnotetext{
${ }^{32}$ FERNÁNDEZ ARÉVALO, Luis y NISTAL BURÓN, Javier; Manual de...cit.; pág. 787.

${ }^{33}$ Introducido en la LO 1/2015, de 30 de marzo, que modifica el art. 76 LOGP tácitamente, al oponerse al mismo, disponiendo que será el tribunal quien acordará la suspensión de la ejecución de la pena de prisión permanente revisable - libertad condicional -. Vid. En MIR PUIG, Carlos; Derecho Penitenciario...cit.; pág. 231.

${ }^{34}$ Tan sólo la DA $5^{\text {a }}$ de la LOPJ (reformada por LO 7/2003) se ocupa de la materia procesal en este ámbito, pero limitada a los Recursos contra las Resoluciones de los JVP, con regular fortuna a tenor de los problemas interpretativos que suscita. Esta última disposición también ha sido modificada por la LO 5/2003, de 27 de mayo, mediante la cual se crean los Juzgados Centrales de Vigilancia Penitenciaria (JCVP), atribuyéndoles competencias en el ámbito de los delitos instruidos y enjuiciados por la Audiencia Nacional (AN), según se declara en la Exposición de Motivos, "con el fin de conseguir una unificación de criterios en el marco del control de las penas". Vid. en PÉREZ CEPEDA, Ana Isabel; Lecciones...cit.; pág. 269.
} 
f) El RP, de desarrollo de la LOGP, aprobado por RD 190/1996, de 9 de febrero, y que viene a derogar el aprobado por RD 1201/1981, de 8 de mayo, parcialmente reformado por RD 787/1984, de 28 de marzo.

g) $\mathrm{RD}$ 840/2011, de 17 de junio por el que se establecen las circunstancias de ejecución de las penas de trabajo en beneficio de la comunidad y de localización permanente en Centro penitenciario de determinadas medidas, así como de la suspensión de la ejecución de las penas privativas de libertad y sustitución de penas.

h) La Jurisprudencia del Tribunal constitucional en materia penitenciaria. Próximamente, la LO reguladora del procedimiento ante los juzgados de vigilancia penitenciaria. ${ }^{35}$

\section{VI.LAS FUNCIONES DEL JVP}

De la literalidad del art. 76.1LOGP se deducen 4 funciones a cargo del Juez de JVP que son las siguientes:

A) Hacer cumplir la pena impuesta.

B) Resolver los recursos referentes a las modificaciones que pueda experimentar (la pena) con arreglo a lo prescrito en las leyes y reglamentos.

C) Salvaguardar los derechos de los internos.

D) Corregir los abusos y desviaciones que en el cumplimiento de los preceptos del régimen penitenciario puedan producirse.

\section{A. HACER CUMPLIR LA PENA IMPUESTA.}

El núcleo esencial de las funciones del JVP, de acuerdo a FERNÁNDEZ ARÉVALO-NISTAL BURÓN se encuentra contenido en el art. 76.1 LOGP, y es el que caracteriza la vertiente jurisdiccional en la ejecución de las penas privativas de libertad ya que no sólo atribuye al JVP el hacer cumplir la pena impuesta, sino que además determina que debe hacerlo asumiendo las funciones que corresponderían a los Jueces y

${ }^{35}$ RODRÍGUEZ ALONSO, Antonio-RODRÍGUEZ AVILÉS, Juan Antonio; Lecciones...cit.; págs. 54 y s. 
Tribunales sentenciadores. Bajo este planteamiento, el apartado primero del artículo en comento tiene una clara relación con el inciso a) de su apartado segundo.

Existen excepciones con respecto a la regla que faculta a los JVP para asumir funciones que le corresponderían a los Jueces y Tribunales sentenciadores. Esas excepciones son el licenciamiento definitivo y excarcelación, que el art. 17.3 LOGP optó porque continuase residiendo la competencia en éstos últimos, al decir que "para proceder a la excarcelación de los condenados será precisa la aprobación de la libertad definitiva por el Tribunal sentenciador...”. También mantiene competencias en la liquidación de condena y en la refundición de condenas. ${ }^{36}$

Ahora bien, debe atenderse, acudiendo a una interpretación exegética, que la competencia del JVP, con respecto a las penas privativas de la libertad, entendiendo por tales las establecidas en el art. $35 \mathrm{CP}$, van referidas a las siguientes consecuencias jurídicas del delito:

- prisión

- responsabilidad personal subsidiaria por impago de multa

- la localización permanente ${ }^{37}$

Y los supuestos de ingreso en prisión como consecuencia de la revocación de:

○ suspensión de condena (art. $84 \mathrm{CP}$ )

○ sustitución de condena ( art. $88 \mathrm{CP}$ )

De lo anteriormente expuesto, podemos concluir que, la competencia de los JVP solo se extiende en plenitud a los reclusos penados. Respecto de los detenidos y presos,

\footnotetext{
${ }^{36}$ PÉREZ CEPEDA, Ana Isabel; Lecciones...cit.; págs. 270 y ss.

${ }^{37} \mathrm{El}$ art. $35 \mathrm{CP}$ vigente, incorpora ahora la referencia a la prisión permanente revisable, prevista para los supuestos de asesinato regulados en el art. 140 y en los arts. 485, 605, 607.1 y 2. Con respecto al art. 35 del CP, deberá tenerse en cuenta el nuevo art. 92 del mismo cuerpo legal, introducido en la LO 1/2015, de 30 de marzo, que modifica el art. 76 LOGP tácitamente, al oponerse al mismo, disponiendo que será el tribunal quien acordará la suspensión de la ejecución de la pena de prisión permanente revisable - libertad condicional -. Vid., la clasificación propuesta por RACIONERO CARMONA, Francisco; Derecho Penitenciario y Privación de Libertad, una Perspectiva Judicial; 1 ${ }^{\mathrm{a}}$ ed.; Ed. Dykinson; Madrid; 1999; pág. 75, y, por otro lado, los comentarios sobre el art. 35 CP de CORCOY BIDASOLO, Mirentxu- MIR PUIG, Santiago; Comentarios al Código Penal. Reforma LO 1/2015 Y LO 2/2015; $1^{\mathrm{a}}$ ed.; Ed. Tirant lo Blanch; Valencia; 2015; pág 197; y MIR PUIG, Carlos; Derecho Penitenciario...cit.; págs. 231.
} 
alcanza exclusivamente a la materia de "régimen" (prestaciones y deberes de la Administración, comunicaciones, disciplina, etc.), dependiendo en lo demás (por ejemplo, permisos de salida) del órgano judicial de quien dependan. ${ }^{38}$

Dentro de las de las funciones generales de ejecución se incardinan las competencias de aprobación de los proyectos de refundición material de condenas contemplada en el art. 193.2 RP y las decisiones de abono de prisión preventiva sufridas en otra causa - que fue reconocida por la jurisprudencia del TS en 1990 y que se ha visto avalada por el art. $58 \mathrm{CP}$ - y para un sector doctrinal y de JVP, aunque esto se discute, la competencia de dictar órdenes de busca y captura relativa al penado evadido. $^{39}$

B. RESOLVER LOS RECURSOS REFERENTES A LAS MODIFICACIONES QUE PUEDA EXPERIMENTAR (LA PENA) CON ARREGLO A LO PRESCRITO EN LAS LEYES Y REGLAMENTOS.

La función a la que se alude en este subcapítulo es considerada por RACIONERO CARMONA como un supuesto típico de una modificación legislativa que suponga la revisión de las condenas para hallar la ley más favorable. Sin embargo, aclara el autor que ahora, tal revisión está a cargo de los Tribunales sentenciadores y por lo tanto, se puede hablar, en este caso de una facultad inaplicada por los JVP.

Cabe añadir que otras posibles modificaciones de la pena, señaladamente la Libertad Condicional y Redención de penas por el trabajo - en la medida en que esta institución continúa aplicándose a los ejecutoriados conforme al CP 73 - si son de la competencia de los JVP. ${ }^{40}$

\section{LA ACTIVIDAD DE TUTELA JUDICIAL EFECIVA EN EL ÁMBITO PENITENCIARIO.}

Atendiendo al método exegético, como instrumento de interpretación de la legislación penitenciaria vigente, propuesto para el presente estudio, las funciones

\footnotetext{
${ }^{38}$ RACIONERO CARMONA, Francisco; Derecho...; pág. 76.

${ }^{39}$ FERNÁNDEZ ARÉVALO, Luis y NISTAL BURÓN, Javier; Manual de...cit.; pág. 779.

${ }^{40}$ RACIONERO CARMONA, Francisco; Derecho...; pág. 76.
} 
identificadas con los incisos C) y D) del subcapítulo anterior, se presentan estrechamente concatenadas con lo regulado en una serie de preceptos del RP, relativos a la organización de los establecimientos, al régimen y al tratamiento, en los que se establece la obligatoriedad de poner en conocimiento del JVP actuaciones de la Administración que pueden suponer restricciones en los derechos de los internos. La finalidad que persigue es anticipar el conocimiento de dicho Juez sobre las medidas que se adopten y las razones en que se fundamentan para que si lo entiende necesario recabe los informes que procedan y adoptar las medidas que exija el respeto a los derechos de los internos. ${ }^{41}$

Bajo esta perspectiva, hay que añadir que los derechos de los internos, deben considerarse en principio, en su versión amplificada, puesto que aun cuando la CE en su art. 25.2 se refiere a los derechos fundamentales no limitados por el contenido del fallo condenatorio, el sentido de la pena y el ordenamiento penitenciario, también es verdad que, a partir de que la sentencia penal deviene firme y, en consecuencia ejecutable en el ámbito carcelario, nace una relación jurídica entre la Administración y el penado que hace necesario también salvaguardar derechos ordinarios dispersos a todo lo largo y ancho de la LOGP y el RP. Por ejemplo, permisos de salida, formular peticiones y quejas, vestir sus propias ropas, limitación legal en el uso de medios coercitivos y un etcétera tan largo como imposible de resumir o sistematizar ahora.

Por otro lado, la corrección de abusos y desviaciones que puedan producirse en el régimen penitenciario deviene también en una facultad amplísima pues el "régimen" es el conjunto de norma, que regulan la convivencia y custodia de los internos y el orden dentro de los establecimientos penitenciarios, determinando los derechos y prestaciones que corresponden al recluso por su condición general de ciudadano del Estado. Es decir, comprende la organización general, trabajo, asistencia sanitaria, régimen disciplinario, recompensas, permisos de salida, información, quejas y recursos, comunicaciones y visitas, asistencia religiosa e instrucción y educación. En resumen, el Título II de la LOGP. ${ }^{42}$

\footnotetext{
${ }^{41}$ RODRÍGUEZ ALONSO, Antonio-RODRÍGUEZ AVILÉS, Juan Antonio; Lecciones...cit.; pág. 58.

${ }^{42}$ RACIONERO CARMONA, Francisco; Derecho...; pág. 76 y ss. Por su parte RODRÍGUEZ ALONSORODRÍGUEZ AVILÉS recogen la literalidad del art. 37.1 del RP para definir el régimen: "por régimen penitenciario se entiende el conjunto de normas o medidas que persiguen la consecución de una
} 
Pues bien, para lograr el objetivo de tutela judicial efectiva desde la entrada en vigor de la DA $5^{\text {a }}$, en su interpretación exegética, viene a significar la creación de un sistema de recursos de impugnación de índole diversa con competencias, a su vez, interrelacionadas con autoridades distintas a la original jurisdicción penitenciara, que a continuación se plantean, no sin antes exponer algunos matices derivados de la producción legislativa posterior a la entrada en vigor de la LOGP, mismos que han venido a generar múltiples opiniones en la doctrina, y que intentaré resumir:

Debido a la falta de normativa que regulase los procedimientos ante los JVP, el Tribunal Supremo (desde ahora TS) promulga el 8 de octubre de 1991 unas Prevenciones dirigidas a los JVP sobre las garantías a observar en estos procedimientos los principios generales del Derecho: derecho a la defensa y asistencia letrada, ser informado de la medida a imponer, publicidad, derecho a utilizar los medios de prueba pertinentes, evitación de toda dilación y prohibición de todo asomo de indefensión. Por su parte la Fiscalía General del Estado dicta el 22 de octubre la Consulta 2/1981 sobre el ejercicio del Ministerio Fiscal (desde ahora MF) en los nuevos JVP, y el 17 de noviembre es la Dirección General de Instituciones Penitenciarias (desde ahora DGIP) la que por vía circular da normas a los Centros Penitenciarios al respecto. ${ }^{43}$

Posteriormente, en 1985, tal y como quedó explicado en el capítulo II del presente artículo, entró en vigor la Ley Orgánica del Poder Judicial, en concreto la DA $5^{\mathrm{a}}$ y su art. 82.1.3 - naturalmente había que tener presente también la LECrim -, contiene la escasa regulación normativa procesal existente, limitándose exclusivamente a los recursos deducibles contra las resoluciones de los JVP. Actualmente, la LO 5/2003, de 27 de mayo, ha modificado la estructura y planta de los JVP, introduciendo una nueva clase los Juzgados Centrales de Vigilancia Penitenciaria (desde ahora JCVP). Para la introducción de estos nuevos órganos ha sido necesario modificar la LOPJ (arts.

convivencia ordenada y pacífica que permita alcanzar el ambiente adecuado para el éxito del tratamiento y la retención y custodia de los reclusos". Vid., en AVILÉS RODRÍGUEZ ALONSO, Antonio-RODRÍGUEZ AVILÉS, Juan Antonio; Lecciones ...cit.; pág. 143.

${ }^{43}$ LEGANÉS GÓMEZ, Santiago; La evolución de la clasificación penitenciaria. Premio Nacional Victoria Kent. Año 2004. Ministerio del Interior. DGIP. Ed. Secretaría General Técnica; 2005; pág. 185. 
$65,82,94$ y DA $5^{\mathrm{a}}$ ) que atribuye a la $\mathrm{AN}$ el conocimiento de los recursos contra las resoluciones de los JCVP (art. 65). ${ }^{44}$

Toda esta producción legislativa, como es de suponerse, es derivada del art. 24.1 de la $\mathrm{CE}$, que se traduce en el principio constitucional identificado como "tutela judicial efectiva", creado a través de la jurisprudencia del Tribunal Constitucional y que se traduce en el ámbito de la ejecución de las penas y medidas de seguridad en la disponibilidad legal de medios de impugnación a disposición de los reclusos y de quien esté legalmente facultado para interponerlos, de conformidad con la legislación penitenciaria vigente, e incluso, en textos internacionales vigentes ratificados por España y que recogen y consolidan dicha doctrina jurisprudencial.

En este sentido, MARTÍN DIZ afirma que del estudio y tratamiento de las posibilidades de impugnación que los textos penitenciarios conceden a los reclusos se observa una doble faz en cuanto a la actividad del JVP, sus atribuciones en vía de recurso contemplan el conocimiento de la impugnación de actos de la Administración Penitenciaria por parte del recluso o bien directamente la impugnación de determinadas resoluciones del propio JVP, mediante el remedio de reforma ante dicho órgano, o bien en un verdadero recurso en apelación ante el inmediato superior jerárquico como es la Audiencia Provincial (desde ahora AP) de la provincia donde tenga su sede. ${ }^{45}$

\section{a. IMPUGNACIÓN DE ACTOS DE LA ADMINISTRACIÓN PENITENCIARIA} POR PARTE DEL RECLUSO.

La impugnación de actos de la administración penitenciaria por parte de los reclusos es conocida por un sector de la doctrina como "jurisdicción de control contencioso-administrativa", ${ }^{46}$

El Tribunal Constitucional, en la Sentencia de 30.7.1983, reconoce al JVP la condición de "vía normal para salvaguardar los derechos de los internos en las prisiones... contra los actos de la administración penitenciaria...”. Y, como consecuencia de ello, en la STC de 26.4.1993, califica a los JVP de "pieza clave del

\footnotetext{
${ }^{44}$ PÉREZ CEPEDA, Ana Isabel; Lecciones...cit.; pág. 284.

${ }^{45}$ MARTÍN DIZ, Fernando; El Juez...cit. pág. 206.

${ }^{46}$ PÉREZ CEPEDA, Ana Isabel; Lecciones...cit.; pág. 271.
} 
sistema penitenciario", exigiendo su intervención como requisito imprescindible para acceso al recurso de amparo, es decir, a los efectos del art. 43.1 de la Ley Orgánica del Tribunal Constitucional (desde ahora LOTC). En la vertiente de control, el propio artículo en comento fija con carácter general dos atribuciones esenciales: primera, salvaguardar los derechos de los internos; segunda, corregir los abusos y desviaciones que en el cumplimiento de los preceptos del régimen penitenciario puedan producirse. ${ }^{47}$

PÉREZ CEPEDA, añade que la LOGP atribuye al JVP la función de garante efectivo de los derechos de los internos (ya que puede y debe corregir los abusos y desviaciones que apreciare). Por ello, afirma, el JVP "desarrolla un control jurisdiccional, cuyo contenido es más amplio, ya que abarca funciones estrictamente jurisdiccionales y otras que no lo son, respecto de todo lo que se refiere al amparo de los derechos de los internos (penados y preventivos) y específicamente lo relacionado con los beneficios penitenciarios - en la medida que pueden introducir un tratamiento discriminatorio positivo - y la potestad disciplinaria."

Al tratarse de un control sobre actos que, por decirlo de alguna manera, emanan de una autoridad de origen, como lo es la Administración penitenciaria, el JVP, en términos generales, constituye la segunda instancia a la cual recurrir cuando dicha actividad, presumiblemente, constituya violación o menoscabo de los derechos de los internos. Este recurso es llamado por otro sector de la doctrina recurso de alzada ${ }^{48}$.

Por tanto el JVP conoce del recurso de alzada en los siguientes casos:

a) Resolver por vía de recurso las reclamaciones de los internos sobre sanciones disciplinarias, art. 76.2 e): Contra el acuerdo sancionador de la Comisión Disciplinaria cabe recurso ante el JVP (art. 249 RP), quien mediante auto debe confirmar o modificar la sanción; este recurso se puede presentar verbalmente en el

\footnotetext{
${ }^{47}$ Ibidem.

${ }^{48}$ LEGANÉS GÓMEZ, Santiago; La evolución...cit.; pág. 188.Vid., NISTAL BURÓN, Javier; "El recurso de apelación en materia penitenciaria. Su controvertida procedencia contra los autos de los Jueces de Vigilancia desestimatorios de las quejas penitenciarias”. Citado por CERVELLÓ DONDERIS, Vicenta; Derecho...cit.; pág. 147. Vid.; en el mismo sentido MARTÍN DIZ, Fernando; El Juez...cit. pág. 206 y 208.
} 
mismo momento de la notificación o por escrito ante el JVP en los cinco días siguientes a la notificación. ${ }^{49}$

b) Resolver los recursos referentes a clasificación inicial y progresión y regresión de grado, art. 76.2 f): Aprobada la clasificación por el Centro Directivo el interno puede recurrir ante el JVP (art. 103 RP) sin que se indique el plazo de interposición ni la forma de llevarlo a cabo, ya que el único caso donde se señalan los plazos es en el art. 248.b) del RP relativo al supuesto anterior. ${ }^{50}$

Cabe hacer la siguiente aclaración: en el primer caso, las reclamaciones son restringidas a su articulación por los reclusos.

Por el contrario, en el segundo caso, no existe una restricción literal en lo que atañe a los recursos referentes a clasificación inicial, progresiones y regresiones de grado, lo que habilitará la legitimación del Ministerio Fiscal, en concreto contra los acuerdos de clasificación y progresión en tercer grado, que le son todos notificados de conformidad con lo establecido en el art. 107 RP aprobado por RD 190/1996, de 9 de febrero.

\section{b. LA IMPUGNACIÓN DE RESOLUCIONES DEL JVP.}

\section{a’. RECURSO DE REFORMA.}

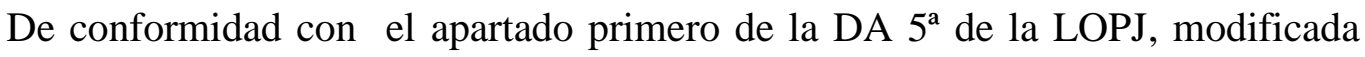
por LO 5/2003, de 27 de mayo, el recurso de reforma está previsto contra todos los Autos del JVP. ${ }^{51}$ Cabe interponerlo en los tres días siguientes a la última notificación (art. 211 LECrim) ante el mismo JVP. Si este recurso se interpone contra Autos que resuelven recurso planteado en materia disciplinaria tiene efecto suspensivo, salvo lo previsto en el art. 44.3 LOGP. $^{52}$ No es necesario abogado ni procurador, si bien, que no

\footnotetext{
${ }^{49}$ CERVELLÓ DONDERIS, Vicenta; Derecho...cit.; pág. 144.

${ }^{50}$ Vid., en este sentido el acuerdo doctrinal en éste y el anterior supuesto por parte de LEGANÉS GÓMEZ, Santiago; La evolución ...cit.; pág. 189.

${ }^{51}$ PÉREZ CEPEDA, Ana Isabel; Lecciones...cit.; pág. 284.

52"Artículo 44. 3. La interposición de recurso contra resoluciones sancionadoras suspenderá la efectividad de la sanción, salvo cuando por tratarse de un acto de indisciplina grave la corrección no pueda demorarse. Los recursos contra resoluciones que impongan la sanción de aislamiento en celda serán de tramitación urgente y preferente."
} 
se necesite asistencia letrada más que en el recurso de apelación, y no en los demás casos, no debería impedir la asistencia jurídica gratuita en todos los procedimientos en los que la intervención letrada no sea obligatoria, ya que lo contrario podría vulnerar el derecho de defensa. ${ }^{53}$

El recurso de reforma es previo al recurso de apelación, aunque en la práctica suelen presentarse en el mismo escrito de reforma la interposición del recurso de apelación. La consecuencia es que si se desestima el de reforma, el propio JVP lo manda directamente a la Audiencia Provincial, y en su caso a la Audiencia Nacional (LO 5/2003, de 27 de mayo) para que se resuelva en apelación. ${ }^{54}$

\section{b’. RECURSOS DE APELACIÓN.}

Existen cuatro reglas generales con respecto a este recurso:

PRIMERA. Todas las resoluciones del JVP tanto las del aparado $2^{\circ}$, como del apartado $3^{\circ}$ de la da $5^{\mathrm{a}} \mathrm{LOPJ}$, serán recurribles tras el de reforma, en apelación excepto las de materia disciplinaria, tramitándose con arreglo a las normas de la LECrim sobre procedimiento abreviado. ${ }^{55}$

SEGUNDA. De conformidad con los mismos apartados del artículo citado en el párrafo inmediato anterior, las resoluciones en materia de ejecución de penas deberán ser dictadas por el Tribunal sentenciador y si los recursos se refieren a régimen penitenciario, resolverá la Audiencia Provincial. ${ }^{56}$

TERCERA. "Si el recurso de apelación se presenta contra resoluciones dictadas por los JCVP, tanto en materia de ejecución de penas como de régimen penitenciario, resolverá siempre la Sala de lo Penal de la Audiencia Nacional por tratarse del Tribunal sentenciador (Ley 5/2003 de 27 de mayo de modificación de la LOPJ) "..."Con esta centralización se quiere evitar la controversia sobre los distintos

\footnotetext{
${ }^{53}$ CERVELLÓ DONDERIS, Vicenta; Derecho...cit.; pág. 148.

${ }^{54}$ Vid., supra nota $\mathrm{n}^{\mathrm{o}} .34$.

${ }^{55}$ MARTÍN DIZ, Fernando; El Juez....cit. pág. 208.

${ }^{56}$ Vid., en este sentido CERVELLÓ DONDERIS, Vicenta; Derecho...cit.; pág. 149.
} 
pronunciamientos de clasificación en las Audiencias Provinciales respecto a internos terroristas. ${ }^{, 57}$

CUARTA. Todos los recursos de apelación contra resoluciones relativas a la clasificación los resolverá el Tribunal sentenciador encargado de la ejecución de la condena (Juez competente para la ejecución puede ser el Juez sentenciador ${ }^{58}$, el Juez de ejecutorias $^{59}$ o el juez de instrucción en los supuestos de conformidad previstos en el art. 801 LECrim.)

Sin embargo, el Auto del TS de fecha 24 de junio de 2005, concluye que "en el aspecto piramidal del subsistema jurisdiccional español, el órgano que resuelva los recursos de apelación no ha de ser uno situado en el mismo nivel del que dictó la resolución recurrida sino en otro superior". 60

El plazo para interponer el recurso es de cinco días y se necesita de abogado, art. 766.3 LECrim. $^{61}$

\section{c'. RECURSO DE QUEJA.}

Procede contra el Auto del JVP que deseche a trámite un recurso de apelación, de conformidad con la LO 7/2003 apartado cuarto de la DA 5 a de la LOPJ. Para su interposición también se requiere la asistencia letrada. Se interpone ante el tribunal sentenciador $^{62}$ (art. 219 LECrim). Interpuesto el recurso, la AP recabará el informe

\footnotetext{
${ }^{57}$ RODRÍGUEZ ALONSO, Antonio-RODRÍGUEZ AVILÉS, Juan Antonio; Lecciones...cit.; pág. 143.
}

${ }^{58}$ La DA $5^{\mathrm{a}}$ en su apartado $2^{\circ}$ establece que en los supuestos en que el penado se encuentre cumpliendo varias penas, podrá interponer recurso de apelación, incluso el de queja, ante el Juez o Tribunal que haya puesto la más grave. Si son varios los Jueces o Tribunales que han impuesto la misma pena a un recluso, la competencia le corresponderá al que de ellos la haya impuesto en último lugar. Vid., en este sentido, PÉREZ CEPEDA, Ana Isabel; Lecciones...cit.; pág. 284. De igual forma comparte el mismo criterio CERVELLÓ DONDERIS, Vicenta; Derecho...cit.; pág. 151.

\footnotetext{
${ }^{59}$ Se han creado en algunas ciudades españolas Juzgados de ejecutorias, los cuales tienen asignadas funciones de la ejecución de las sentencias dictadas por causas por delito, dando lugar a que un Juzgado distinto al que sentenció se ocupe de todos los aspectos relacionados con la ejecución de las penas, así como resolver muchas de las tareas legalmente encomendadas a los Tribunales sentenciadores tales como acumulación de condenas, suspensión de ejecución, sustitución, etc. Vid., ibidem; págs. 152 y 154.
}

${ }^{60}$ PÉREZ CEPEDA, Ana Isabel; Lecciones...cit.; pág. 285.

${ }^{61}$ CERVELLÓ DONDERIS, Vicenta; Derecho...cit.; pág. 151.

${ }^{62} \mathrm{~A}$ este recurso le son aplicables las reglas generales del subcapítulo inmediato anterior. 
correspondiente del JVP, dándose traslado del mismo al Fiscal para que emita un dictamen en el plazo de tres días, cumplido el cual resuelve la AP o la AN. ${ }^{63}$

\section{d’. RECURSO DE CASACIÓN PARA LA UNIFICACIÓN DE DOCTRINA.}

Se introdujo en 2003 y se tramita ante la Segunda Sala de Tribunal Supremo para unificación de doctrina en materia penitenciaria, contra los autos dictados por las Audiencias Provinciales o Audiencia Nacional resolviendo recursos de apelación en materia penitenciaria que no sean susceptibles de casación ordinaria. Casación ordinaria cabe frente a los autos de acumulación de condenas, abono de prisión preventiva o máximo de cumplimiento de condena. ${ }^{64}$

El recurso únicamente puede fundamentarse en la existencia de contradicción entre la doctrina asumida por el auto recurrido y la mantenida en la resolución o resoluciones de contraste ${ }^{65}$, ante ello el TS podrá optar por una de ellas o por una tercera interpretación, teniendo en cuenta que la resolución de este recurso no afectará a las sentencias precedentes. Este recurso sólo podrán presentarlo también el MF y el penado. $^{66}$

\section{e' RECURSO DE AMPARO}

Puede accederse a la jurisdicción constitucional, mediante la interposición de recurso de amparo contra las resoluciones dictadas en apelación por la AP o, en su caso, la $\mathrm{AN}$, cuando se menciona la infracción de un derecho fundamental, previo, en su caso, lo dispuesto en el art. 241.1 y 2 de la LOGP, recurso de amparo que debe interponerse ante el propio Tribunal Constitucional. ${ }^{67}$

\section{f’. RECURSO ANTE EL TRIBUNAL EUROPEO DE DERECHOS HUMANOS}

\footnotetext{
tribunal sentenciador (art. 233 y ss. LECrim)

${ }^{64}$ CERVELLÓ DONDERIS, Vicenta; Derecho....cit.; pág. 153.

${ }^{65}$ LEGANÉS GÓMEZ, Santiago; La evolución ...cit.; pág. 201.

${ }^{66}$ CERVELLÓ DONDERIS, Vicenta; Derecho...cit.; pág. 153.

${ }^{67}$ MIR PUIG, Carlos; Derecho Penitenciario...cit.; págs. 242.
}

${ }^{63}$ Vid., en CERVELLÓ DONDERIS, Vicenta; Derecho...cit.; pág. 152; y PÉREZ CEPEDA, Ana Isabel; Lecciones...cit.; pág. 286. Contrario a esta postura LEGANÉS GÓMEZ, Santiago; La evolución...cit.; pág. 199. Manifiesta que quien resuelve el recurso después de rendido el informe por parte del MF es el 
Usualmente se acude a esta instancia por vulneración de los derechos recogido en el Convenios europeo de Derechos Humanos, siendo lo más frecuente la impugnación por vulneración del art. 3 (prohibición de torturas, malos tratos, penas inhumanas y degradantes) y el art. 8 (derecho a la vida privada, vida familiar, domicilio y correspondencia). ${ }^{68}$

Algunos autores afirman que se pueden recurrir ante este Tribunal, incluso en materia de clasificación penitenciaria, si un interno se siente víctima de la violación de su derecho a la libertad por estimar que su clasificación no se ajusta a Derecho.

A este Tribunal no podrá recurrirse sino después de agotar las vías de recursos internas, tal como se entiende según los principios de derecho internacional generalmente reconocidos y en un plazo de seis meses a partir de la fecha de la resolución interna definitiva, que en España será el Tribunal Constitucional. ${ }^{69}$

\footnotetext{
${ }^{68}$ CERVELLÓ DONDERIS, Vicenta; Derecho...cit.; pág. 153 y ss.

${ }^{69}$ LEGANÉS GÓMEZ, Santiago; La evolución ...cit.; pág. 202.
} 